\title{
Increasing Engagement of Underrepresented Groups Using a Novel Mathematics Communication Tool
}

\author{
Marco Pollanen, Sohee Kang, and Bruce Cater
}

\begin{abstract}
Many recent studies, based largely on face-to-face classroom experiences, extol the benefits of new interactive pedagogical models, including peer-based learning. Others have shown that out-of-class student-teacher interaction (e.g., office hour attendance) leads to improvements in many key academic measures, including student performance, retention, and satisfaction. At the same time, however, it has been shown that, relative to their male peers, women are less likely to engage in both in- and out-of-class discussion in post-secondary mathematics and statistics courses.

In this paper, we discuss our experience with a mathematics service course in which online communication technology that allowed for anonymity was used. This technology dramatically improved office-hour participation rates, and students reported that it helped alleviate their anxieties surrounding communication. We then explore how these ideas can be extended to develop new communication models for the technologically-enhanced class - models that may help overcome social barriers to create a more inclusive student-centred environment, leading to further democratization of learning, including increased participation by women.
\end{abstract}

Index Terms-Mathematics education, online communication, statistics education, student engagement.

\section{INTRODUCTION}

Science, Technology, Engineering, and Mathematics (STEM) careers are often seen as lucrative and rewarding. Those careers, however, tend to be male-dominated. To address this problem, recent decades have seen many efforts to increase the number female students in post-secondary STEM disciplines. Despite these efforts, women exit the STEM disciplines at the points of both the transition from secondary to post-secondary and the transition from undergraduate to graduate studies. Moreover, attrition rates during post-secondary STEM programs are higher for females than for males [1]. And this attrition continues into the job market.

One reason for these attrition rate differences may be that male and female students have different educational experiences. In particular, female students interact with their instructors at lower rates than do their male peers. In the next

Manuscript received September 25, 2017; revised December 19, 2017. This work was supported by a research grant from eCampus Ontario.

Marco Pollanen is with the Department of Mathematics, Trent University, Peterborough, Canada (e-mail: marcopollanen@trentu.ca).

Sohee Kang is with the Department of Computer and Mathematical Sciences, University of Toronto Scarborough, Toronto, Canada (e-mail: soheekang@utsc. utoronto.ca).

Bruce Cater is with the Department of Economics, Trent University, Peterborough, Canada (e-mail: bcater@trentu.ca). section, we review the literature on student-teacher communication for female students. We follow that up with a discussion of the importance of student-teacher interaction. We then introduce a technology-assisted communication model that allows for anonymized communication that, we argue, has the potential to increase student-teacher interaction for all students and, in particular, female students.

\section{THE DISPARITY OF VISIBILITY AND ENGAGEMENT IN QUANTITATIVE COURSES}

In every STEM discipline, male faculty outnumber female faculty [2], and women faculty tend to have lower visibility, participating in fewer and less prestigious conferences [3]. This problem with visibility and engagement extends into the classroom.

In STEM courses, both male and female faculty members are likely to spend more time mentoring male students and responding to emails from male students, and they are more likely to call on males in the class [2]. In the study of Biology, it has been shown in surveys that, even after controlling for outspokenness and academic performance, male students are on a whole (mainly due to an overestimation by other male students) seen as more knowledgeable [2]. It is possible that this gender bias results in reducing the confidence of female students. This may be one reason why, although Biology is one of the few sciences in the US where women are in the majority (60\% of the class), and even after controlling for performance, women exit Biology programs at a higher rate than do male students [3]. This lack of confidence can be seen in studies on engagement in courses, where female students, relative to their male peers, ask fewer questions, feel less comfortable asking questions, and take on fewer leadership roles in small group work [4].

While the majority of Biology majors are female, this is the exception rather than the rule in STEM disciplines. For example, despite the desire to increase the number of women in STEM fields, 18 percent of computer science graduates in the US are women, down from 37 percent in 1985 [5]. Here, once again, men dominate the conversation in the traditional classroom [5], with female undergraduate computer science students asking 37 percent fewer questions than their male peers. This gap persists or even grows at the graduate level, with female computer science graduate students asking 42 percent fewer questions than their male classmates.

Notably, this gender-based gap does not seem to exist in social sciences and humanities courses [6]. And although specific data are not available for highly quantitative courses - Mathematics, Statistics, and Physics - it is the experience of the authors that the situation is similar, or perhaps worse. 


\section{IMPORTANCE OF STUDENT-TEACHER INTERACTION}

Given the digital communication revolution, the question of whether student-instructor and student-student interactions have a positive impact on the learning experience is important. After all, if the answer is "no", then what advantage does a post-secondary lecture provide over merely watching pre-recorded videos? A partial answer to that question lies in the many studies, based largely on face-to-face classroom applications, that establish the benefits of new interactive pedagogical models, including peer-based learning [7]. Others have shown that out-of-class student-teacher interaction (e.g., office hour attendance) leads to improvements in many key academic measures, including student performance, retention, and satisfaction [8] while students themselves overwhelmingly show an interest in greater online communication with their professor [9].

The importance of interaction and communication in courses rich in quantitative content is evidenced by the significant supporting resources universities allocate to such courses. Quantitative service courses, for example, are typically assigned a disproportionate level of tutorial and teaching assistant resources. There are usually counselling and academic skills programs in place to deal with general numeracy skills, and there are almost always mathematics and statistics tutorial centres available to deal with specific course content.

Given the importance of interaction both inside and outside the classroom, it is important to ask whether there are barriers to communication that inhibit this interaction. We have already seen that gender is an issue in STEM courses. English language learners, including many international students, may face barriers to communication due to language skills or as a result of shyness or cultural differences. Other barriers in STEM courses, including mathematically rich courses, could be the heavily symbolic content that may hinder online or spoken communication. And, of course, math anxiety may also play a role.

Rarely are classroom supports replicated for online learners. This is particularly so in online symbolic- and diagrammatic-rich courses, where the level of interaction between students and instructors is more constrained by what is technologically possible, than it is driven by what is pedagogically best.

Intuitive technologies for interacting with symbolic and diagrammatic course content are not currently available. And with the paradigm shift to mobile devices, the interface limitations of smartphones and tablets have only made it more difficult to create symbolically rich content. As a result of these technological limitations, there has been very little adoption of online communication tools in the quantitative sciences [10], and almost no adoption of the social media options that are now commonly used in non-quantitative courses [11].

In post-secondary education, mathematics courses are typically a requirement for science majors, and basic statistics courses are often required for majors in data-driven sciences and social sciences. An overwhelming majority of students, however, present at least mild math or statistics anxiety that transcends the level of study. About $85 \%$ of students in an introductory undergraduate mathematics course suffer from math anxiety [12], while up to $80 \%$ of graduate students in the social and behavioral sciences suffer from statistics anxiety [13].

This feeling of tension when exposed to quantitative problems interferes with the ability to manipulate or solve these problems, with resulting implications for performance, low statistical self-efficacy, and the delaying of enrollment in required courses [14].

\section{MODELS FOR INCREASING COMMUNICATION AND ENGAGEMENT}

One opportunity that exists for increasing communication and engagement is the use of technology. In the case of mathematics and statistics, however, this presents unique challenges. While other areas of communication on the Internet have evolved at an astonishing pace, communicating quantitative subjects online still poses formidable challenges, as outlined in [15]. There are a number of reasons for this. First, there are hundreds of mathematical symbols, many of which have no commonly accepted textual equivalent and must therefore be described. Second, the inherently two-dimensional structure of mathematical notation requires spatial relationships between symbols that are difficult to communicate using simple text alone.

An online app, enVision, allowing mathematics to be communicated online, was introduced in [10] and was subsequently studied for use in online office hours for introductory mathematics courses [16].

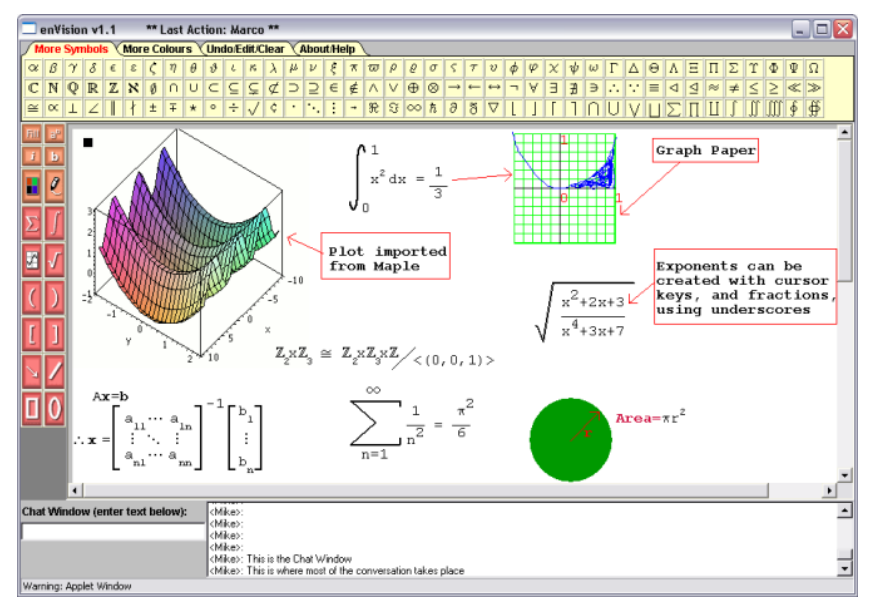

Fig. 1. The enVision web-based app for online office hours in mathematics.

It was shown that through the use of enVision, office hour attendance increased dramatically. Typically, only about $10 \%$ of students might attend an office hour at any time during a semester and this contact is usually brief and superficial [8]. Using enVision, by contrast, it was found that some $40 \%$ of students would attend a single office hour, with many staying for the entire hour. And in surveys of online office hours in a mathematics service course, students reported many reasons for this: convenience, comfort, and access to resources.

"[the instructor] can explain the questions to multiple people at once, which is convenient because people usually have the same questions." 
"I'm much more comfortable with the online sessions."

"Online is less personal which can be good for a lot of students."

“... you can stay in your room with all your resources."

“Online Office Hours are more convenient..."

One of the features of the enVision sessions was that they allowed for students to participate anonymously. Importantly, in surveys, many students discussed how this helped alleviate their anxieties:

"...the student will be more confident in asking questions without embarrassment of asking a 'stupid' question."

“...It's easier to risk asking something dumb when your prof and your friends don't know it's you."

“...if someone is embarrassed to ask questions they don't have to worry about it."

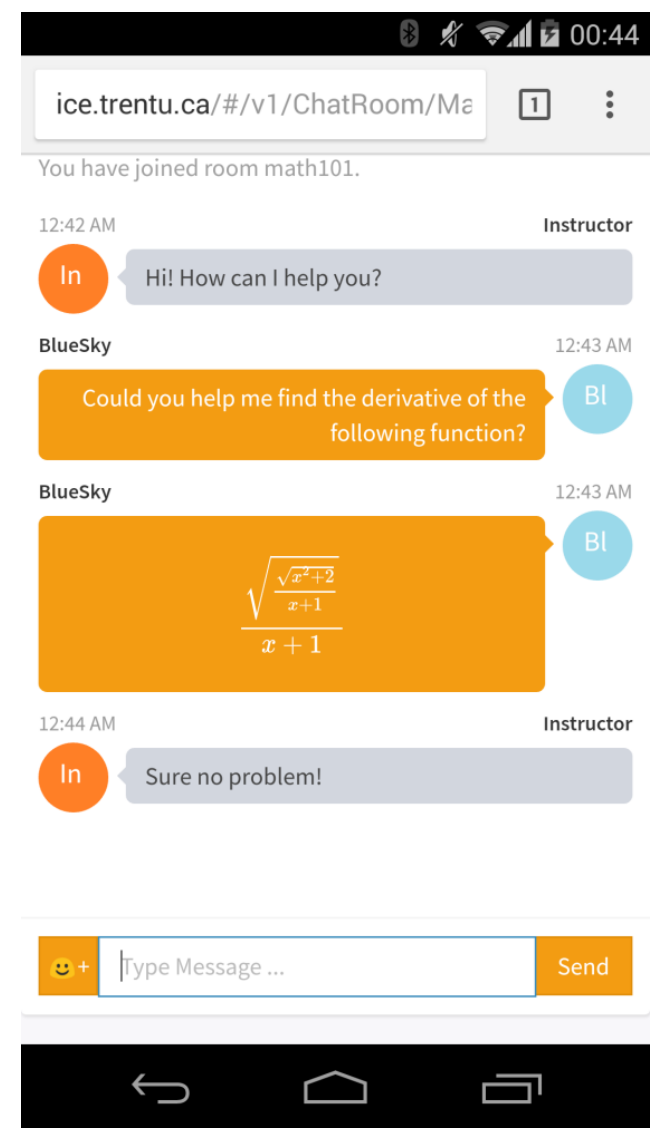

Fig. 2. A screenshot from the chat-screen for the mobile version of MC2 (mathematics classroom collaborator) which implements iCE (interface for collaborative equations) [17].

While [16] introduced anonymity into office hours in mathematics courses, and showed that it could result in much greater participation and lower anxiety, the gender of survey participants was not collected. More recently, [18] studied the use of anonymity in group collaboration in computer science courses and showed that it led to greater participation and learning outcomes, but they too did not specifically study gender gaps. [5], on the other hand, did study gender with respect to the use of anonymity with the discussion tool Piazza among computer science and STEM students, and found that female students were more likely to use the anonymity feature of the software than their male counterparts. However, that study did not specifically address quantitative courses and math anxiety.

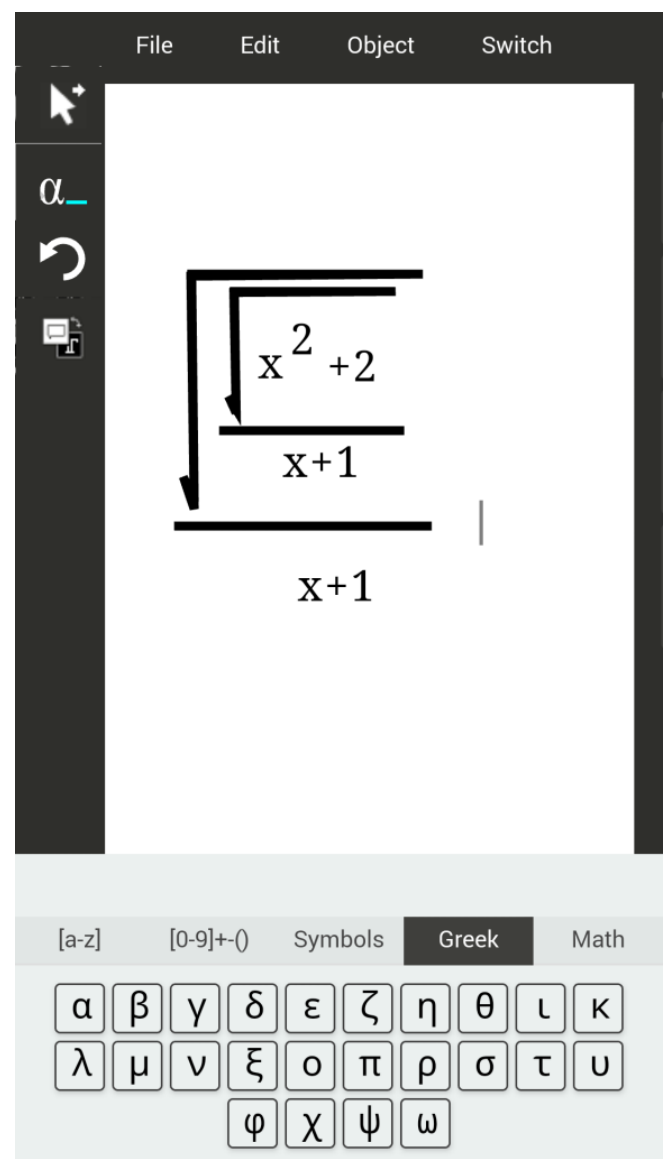

Fig. 3. A screenshot from the equation editor for the mobile version of iCE (interface for Collaborative Equations).

\section{DISCUSSION/CONCLUSION}

The literature makes it clear that active learning - in particular, two-way communication - is an integral part of creating an optimal learning environment. But in STEM subjects, there appear to be barriers to communication that prevent women from having an equal voice inside, and perhaps outside, the classroom. Particularly in the quantitative sciences, where communication may be more subdued due to math or statistics anxiety, women may be constrained from achieving their full potential. One possibility for increasing communication is through the use of online technology and the anonymity that that technology provides. However, mathematics communication requires specialized user interfaces for input.

With the advent of smartphones and tablets, it has become necessary to revisit the design of user-friendly interfaces for mathematical collaboration [15]. Recently, a prototype interface for mathematical collaboration (called iCE: interface for Collaborative Equations) has been developed for smartphones by the authors (see Fig. 2 and Fig. 3). It allows for easier entry and communication of mathematical 
expressions on all devices, ranging from smartphones to desktop computers. The plan is to integrate this interface into a number of different learning tools, such as:

1) A tool allowing for anonymous office hours in quantitative courses or mathematics/statistics help centres

2) A tool allowing students to collaborate with each other in discussions using anonymously

3) A tool allowing students in class to anonymously send questions to their professor in class

Research into the use of anonymity in mathematics and statistics courses is in its infancy, and further technologies to enable easy anonymous communication and interaction in quantitative subjects still needs to be developed. Also, more studies are needed in the mathematical sciences, particularly ones similar to the studies in biology and computing that take into account gender as a factor in engagement. The results might also benefit other identifiable groups of students, such as English language learners. Hopefully, the development of new online tools for mathematics and statistics will be a stepping stone into narrowing the STEM gender gap in engagement.

\section{REFERENCES}

[1] A. Gillen and C. Tanenbaum, "Exploring gender imbalance among STEM doctoral degree recipients," Washington, DC: American Institutes for Research. 2014.

[2] D. Z. Grunspan, S. L. Eddy, S. E. Brownell, B. L. Wiggins, A. J. Crowe and S. M. Goodreau, "Males under-estimate academic performance of their female peers in undergraduate biology classrooms," PloS one, vol. 11, no. 2, 2016.

[3] S. L. Eddy and S. E. Brownell, "Beneath the numbers: A review of gender disparities in undergraduate education across science, technology, engineering, and math disciplines," Physical Review Physics Education Research, vol. 12, no. 2, 2016.

[4] S. L. Eddy, E. E. Brownell, P. Thummaphan, M. C. Lan, and M. P. Wenderoth, "Caution, student experience may vary: social identities impact a student's experience in peer discussions," CBE-Life Sciences Education, vol. 14, no. 4, 2015.

[5] P. Sankar, J. Gilmartin, and M. Sobel, "An examination of belongingness and confidence among female computer science students," ACM SIGCAS Computers and Society, vol. 45, no. 2, pp. 7-10, 2015.

[6] P. Blog, "STEM confidence gap," 2015.

[7] E. Mazur, "Farewell, lecture?" Science, vol. 323, no. 5910, pp. 50-51, 2009.
[8] M. K. Nadler and L. B. Nadler, "Out-of-class communications between faculty and students: A faculty perspective," Communication Studies, vol. 51, no. 2, pp. 176-188, 2000.

[9] L. Helvie-Mason, “Office hours: 'There's an App for that?!': Student perceptions of faculty channels for out-of-class communication," International Journal of Instructional Technology and Distance Learning, vol. 9, 2012.

[10] M. Pollanen, "Interactive Web-based mathematics communication," Journal of Online Mathematics and its Applications, vol. 6, 2006.

[11] S. Aydin, "A review of research on Facebook as an educational environment," Educational Technology Research and Development, vol. 60, no. 6, pp. 1093-1106, 2012.

[12] A. B. Perry, "Decreasing math anxiety in college students," College Student Journal, vol. 38, no. 2, 2004.

[13] A. J. Onwuegbuzie and V. A. Wilson, "Statistics anxiety: Nature, etiology, antecedents, effects, and treatments - A comprehensive review of the literature," Teaching in Higher Education, vol. 8, no. 2, pp. 195-209, 2003.

[14] A. S. Williams, "Statistics anxiety and instructor immediacy," Journal of Statistics Education, vol. 18, no. 2, pp. 1-18, 2010.

[15] M. Pollanen, J. Hooper, B. Cater, and S. Kang, "A tablet-compatible web-interface for mathematical collaboration," Lecture Notes in Computer Science 8592, pp. 614-620, 2014.

[16] J. Hooper, M. Pollanen, and H. Teismann, "Effective online office hours in the mathematical sciences," MERLOT Journal of Online Learning and Teaching, vol. 2, no. 3, pp. 187-194, 2007.

[17] M. Pollanen, S. Kang, B. Cater, Y. Chen, and K. H. Lee, "MC2: Mathematics classroom collaborator," in Proc. MathUI 2017, 2017.

[18] B. S. Jong, C. H. Lai, Y. T. Hsia, and T. W. Lin, "Effects of anonymity in group discussion on peer interaction and learning achievement," IEEE Transactions on Education, vol. 56, no. 3, pp. 292-299, 2013.

Marco Pollanen is a professor in the Department of Mathematics at Trent University. He is a leader in the development of innovation in teaching and learning technologies for mathematics. His innovations earned him awards such as the 2009 National Technology Innovation Award and 2014 Desire2Learn Innovation Award.

Sohee Kang is an assistant professor, teaching stream, of statistics in the Department of Computer and Mathematical Sciences at the University of Toronto at Scarborough. She is also the statistics program coordinator in the centre for teaching and learning, and she works on implementing new teaching innovations.

Bruce Cater is an associate professor in the Department of Economics at Trent University as well as dean of arts \& science: Social sciences. and has published extensively in the economics of disability accommodation and education (including recent articles in the Journal of Labor Economics, Education Economics, and the Journal of Public Economic Theory), as well as in the areas of online technology and pedagogy. 